\title{
'Memory and molecular turnover,' 30 years after inception
}

\author{
Richard B Meagher
}

\begin{abstract}
In 1984 Sir Francis Crick hypothesized that memory is recorded in the brain as reversible modifications to DNA and protein, but acknowledged that most biomolecules turn over too rapidly to account for long-term memories. To accommodate this possible paradox he modeled an enzymatic mechanism to maintain modifications on hemi-modified multimeric symmetrical molecules. While studies on the turnover of chromatin modifications that may be involved in memory are in their infancy, an exploration of his model in the light of modern epigenetics produced somewhat surprising results. The molecular turnover rates for two classes of chromatin modifications believed to record and store durable memories were approximated from experiments using diverse approaches and were found to be remarkably short. The half-lives of DNA cytosine methylation and post-translationally modified nucleosomal histones are measured in hours and minutes, respectively, for a subset of sites on chromatin controlling gene expression. It appears likely that the turnover of DNA methylation in the brain and in neurons, in particular, is even more rapid than in other cell types and organs, perhaps accommodating neuronal plasticity, learning, and memory. The machinery responsible for the rapid turnover of DNA methylation and nucleosomal histone modifications is highly complex, partially redundant, and appears to act in a sequence specific manner. Molecular symmetry plays an important part in maintaining site-specific turnover, but its particular role in memory maintenance is unknown. Elucidating Crick's paradox, the contradiction between rapid molecular turnover of modified biomolecules and long-term memory storage, appears fundamental to understanding cognitive function and neurodegenerative disease.
\end{abstract}

Keywords: Methylcytosine, Hydroxymethylcytosine, Post-translational modification, Histones, Acetylation, Nucleosomes

\section{Review}

\section{Chromatin modifications record memories and regulate} synaptic strength

Thirty years ago, in a letter to Nature ('Memory and molecular turnover'), Crick [1] hypothesized that memory is 'stored in the brain' as reversible modifications to DNA and protein that alter 'synaptic strength'. Only in the last decade has it become clear that changes to the epigenome, modifications to chromatin, such as the $5^{\prime}$ methylation $(5 \mathrm{Me})$ of DNA cytosine $(C)$ residues, the post-translational modification (PTM) of nucleosomal histones (for example, acetylation, methylation, phosphorylation), and histone variant specific nucleosome positioning play central roles in memory formation and maintenance and in synapse development [2-5]. Over 100 enzymes and dozens of

Correspondence: meagher@uga.edu

Genetics Department, University of Georgia, Athens, GA 30602, USA macromolecular machines have been identified that control the formation and turnover of chromatin modifications and the critical movement of modified nucleosomes within and between gene sequences. To date, only a few of these alterations to chromatin have been definitively linked to memory formation and maintenance or to the development of neural structures. Several diseases leading to cognitive dysfunction have been associated with genetic defects in epigenetic controls [2,6,7]. Crick's early insight, suggesting that secondary modifications to DNA and protein are important to memory formation and storage, has been widely cited.

\section{The roles of molecular symmetry and turnover rates to} memory duration

Crick expressed particular concern that most known biomolecules 'turn over in a matter of days, weeks or at 
the most a few months' too rapid to account for longterm memories that might last 'tens of years'. To accommodate this apparent weakness in his theory that remote memory was stored in modified DNA and protein, he modeled an enzymatic mechanism for the long-term maintenance of memory based on the modification of multimeric symmetric molecules, akin to the conservation of symmetrically methylated cytosine DNA residues $\left({ }^{5 \mathrm{Me}} \mathrm{C}\right)$ in a CG sequence context (Figure 1). In his example, site-specific DNA methyltransferases (DNMTs) recognize an unmodified cytosine base at a hemimodified site in the antiparallel complementary strands of DNA and modify it, converting ${ }^{5 \mathrm{Me}} \mathrm{CG} / \mathrm{GC}$ to ${ }^{5 \mathrm{Me}} \mathrm{CG} /$ $\mathrm{G}^{5 \mathrm{Me}} \mathrm{C}[8]$. Crick's model highlighting the importance of rapid molecular turnover and molecular symmetry to memory duration has, with few exceptions, been overlooked in the literature $[3,9,10]$. Beyond memory, this model addresses the broader issue of how any cell in any organ maintains its stable identity if its individuality is determined by protein and nucleic acid modifications that turn over rapidly.

\section{The turnover of DNA cytosine methylation}

DNA methylation does indeed contribute to memory formation and maintenance and is required for longterm potentiation of neurons $[3,4,9,10]$. DNA methylation is considered to be one of the more stable chromatin modifications and one of the few, which once newly established, may even contribute to multi-generationally inherited phenotypes and pathologies [11]. Furthermore, DNA methylation is often phylogenetically conserved among recently duplicated gene sequences. Hence, it seems counterintuitive to consider the rapid turnover of cytosine methylation. Complex machinery is involved in the dynamic maintenance of methylation and has been moderately well characterized, some in relation to learning and memory. For example, the DNA cytosine-5-methyltransferases DNMT1, DNMT3a, and

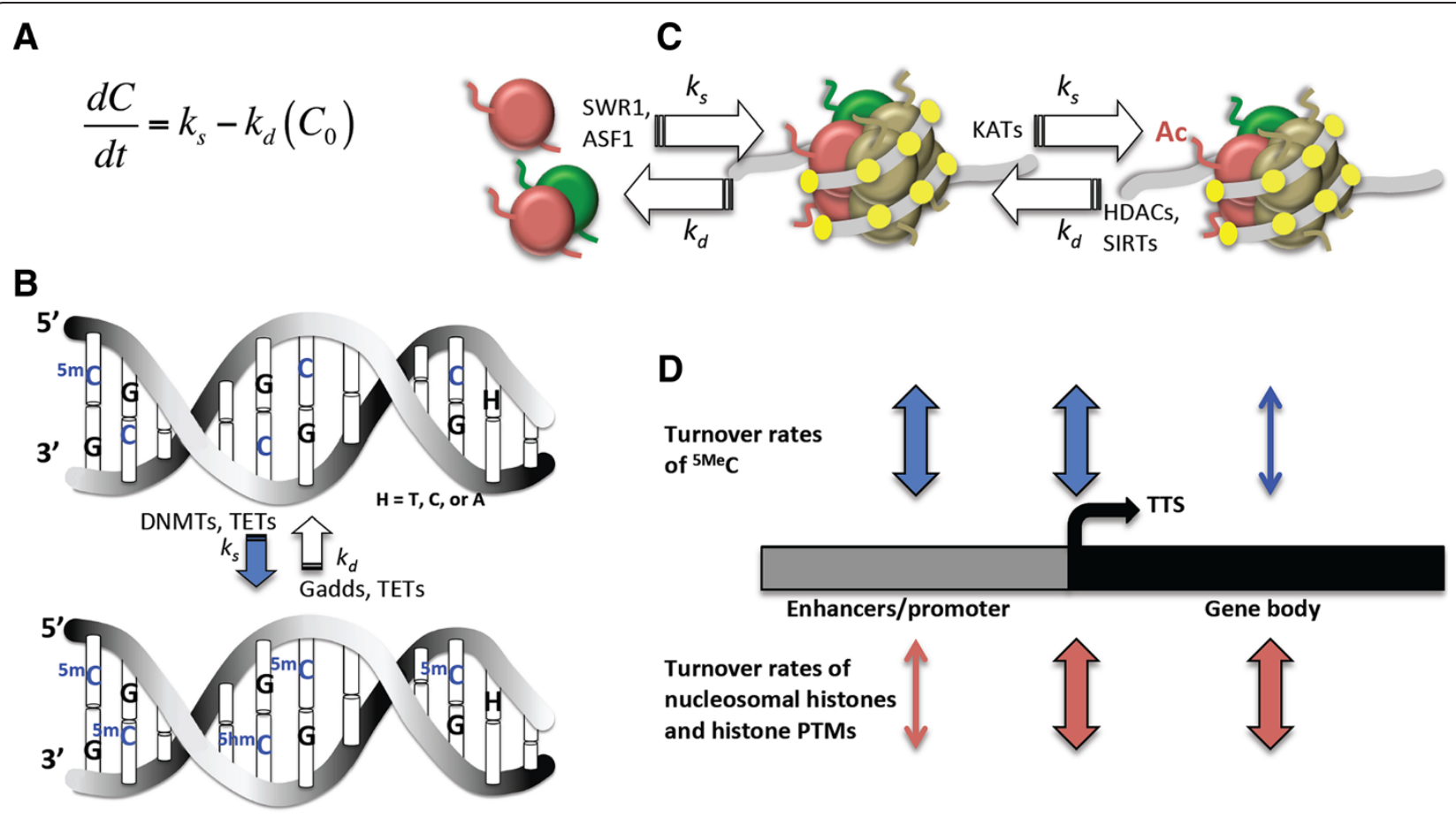

Figure 1 The rapid turnover of DNA cytosine methylation and nucleosomal histones. (A) The turnover rate equation. $d C / d t$ represents the turnover rate of DNA cytosine methylation or nucleosomal histone PTMs, where $C$ is concentration, $t$ is time, $k_{s}$ the synthesis rate, $k_{d}$ the decay rate, and $C_{0}$ the starting concentration. Approximate turnover rates $\left(\frac{d c}{d t}\right)$ (see text) are estimated from the rate of change in modification levels, when neither $k_{s}$ nor $k_{d}=0$. Half-life $\left(t_{1 / 2}\right)$ is the time it takes for a two-fold change in $C_{0}$. (B) The turnover of DNA $5^{\prime}-$ methylcytosine and $5^{\prime}$-hydroxymethylcytosine. The half-life $\left(t_{1 / 2}\right)$ for ${ }^{5 \mathrm{Me}} \mathrm{C}$ residues is estimated in hours or less at selected sites. DNA methyltransferases (DNMTs) contribute to synthesis of ${ }^{5 \mathrm{~m}} \mathrm{C}$ from $\mathrm{C}$, the TETs oxidize ${ }^{5 \mathrm{Me}} \mathrm{C}$ to ${ }^{5 \mathrm{hm}} \mathrm{C}$ and other products discussed in the text, and the Gadds and TETs contribute to the decay of ${ }^{5 \mathrm{Me}} \mathrm{C}$ and ${ }^{5 \mathrm{hm}} \mathrm{C}$ back to $\mathrm{C}$. (C) The turnover of nucleosomal histones and histone PTMs. The half-lives for nucleosomal histones and their PTMs are estimated in tens of minutes or less at selected sites. Nucleosomal histone turnover (left) is catalyzed by chromatin remodeling factors such as SWR1 and ASF1. The turnover of acetylated histone side chains (right) is catalyzed by lysine acetyltransferases (KATs) that add acetyl groups and histone deacetylases (for example, HDACs, SIRT1) that remove acetyl groups. The nucleosome is a symmetrical structure composed of four pairs of histones (large spheres) wrapped in approximately 147 bp of DNA (grey line). DNA dinucleotides that may contribute to nucleosomal positioning and CDI are spaced $10 \mathrm{bp}$ apart (yellow dots). (D) The turnover of chromatin modifications is site specific with rates varying across gene regions, as indicated by the widths of the arrows. 
DNMT3b appear to play a complementary and/or overlapping roles in maintenance and in establishing new methylation patterns involved in learning and memory and in storing memories $[9,12,13]$. DNMTs require the antiparallel symmetry of DNA for their activity (Figure 1B). Non-coding RNAs template de novo cytosine methylation and assist in recruiting DNMTs and RNAdirected DNA methylation machinery (for example, DRM1, DRM2, CMT3) to methylation sites [14-16].

The chemical turnover rates for DNA ${ }^{5 \mathrm{Me}} \mathrm{C}$ may be approximated from pioneering studies that assayed dynamic changes in steady state ${ }^{5 \mathrm{Me}} \mathrm{C}$ levels over relatively short time periods. It is useful to recall that the turnover rate of a molecule $\left(\frac{d c}{d t}\right)$ is equal to the synthesis rate $\left(k_{s}\right)$ minus the decay rate $\left(k_{d}\right)$ multiplied by the starting concentration $\left(C_{o}\right)$ or $\left(\frac{d C}{d t}=k_{s}-k_{d}\left(C_{o}\right)\right)$ (Figure 1A) [17]. The half-life $\left(t_{1 / 2}\right)$ of a molecule is the time it takes for $C_{o}$ to increase or decrease two-fold, when the change in concentration is dependent only upon synthesis or decay. Most reports of dynamic changes to ${ }^{5 \mathrm{me}} \mathrm{C}$ levels set neither the synthesis $k_{s}$ nor decay $k_{d}$ rates to zero, and hence, only approximate the rate of turnover $\left(\frac{d C}{d t} \sim\right)$ or half-life $\left(t_{1 / 2} \sim\right)$. An early indication that DNA methylation regulating relevant gene expression might turn over rapidly comes from a study of changes in the rat hippocampal CA1 region $1 \mathrm{~h}$ following context dependent fear conditioning [13]. $D N M T 3 a$ and DNMT3b transcripts increase significantly. Methylation of a CG island (CGI) in the PP1C promoter increases 45 -fold, while methylation of a CGI in the RELN promoter decreases two-fold within this hour. There is an accompanying reduction in $P P 1 C$ and increase in RELN transcript levels. Hence, the approximate turnover rate for ${ }^{5 \mathrm{Me}} \mathrm{C}$ in these two GCIs is $1 \mathrm{~h}$ or less. The levels of methylation of both promoters returned to base line $24 \mathrm{~h}$ after training. The chemical inhibitor AzaC prevents remethylation by being incorporated into DNA and inhibiting the activity of DNA methyltransferases. Hence, AzaC treatments set the synthesis rate at incorporated sites near to zero so that turnover rates may be more accurately measured $\left(\frac{d C}{d t}=-k_{d}\left(C_{o}\right)\right)$. Hippocampal infusion with limited amounts of AzaC immediately after training completely blocks contextual fear conditioning, greatly reduces the methylation of these two promoter CGIs, and reduces Reelin promoter methylation even lower than with fear conditioning alone. AzaC infusion also reverses changes in PP1 and Reelin transcript levels. This experiment confirms that methylation levels in these CGIs are highly dynamic and suggests turnover rates of less than $1 \mathrm{~h}$. Subsequent studies have further supported the rapid turnover of DNA methylation for a subset of C residues. When $\mathrm{AzaC}$ is added to non-dividing cultured cells, $10 \%$ of total ${ }^{5 \mathrm{Me}} \mathrm{C}$ in the genome is lost after $2 \mathrm{~h}$, but the level of loss increases to only $13 \%$ after $48 \mathrm{~h}$ of treatment, suggesting that only a fraction of total ${ }^{5 \mathrm{Me}} \mathrm{C}$ sites are turning over rapidly [18].

AzaC inhibitor studies may be criticized as increasing rates of DNA repair and perhaps the loss of ${ }^{5 \mathrm{Me}} \mathrm{C}$ by mechanisms not necessarily relevant to normal turnover [19]. Alternative estimates of ${ }^{5 \mathrm{Me}} \mathrm{C}$ minimal turnover rates may be made, independent of the use of DNA methylation inhibitors, based on the approximately hourlong cycles of $p S 2 / T F F 1$ transcript expression observed when this gene is induced in multiple cell types [20]. Hour-long cycles of increased and decreased DNMT3a and $3 \mathrm{~b}$ expression are in phase with decreases and increases in $p S 2$ transcript levels. There are corresponding hour-long cycles of methylation and demethylation at eight out of 19 specific CG sites assayed in the pS2 promoter, which correlate with loss and gain of $p S 2$ transcripts, respectively. Methylation levels change severalfold during each hourly cycle. As methylation levels increase dramatically for 15 to $20 \mathrm{~min}$ of each cycle one may presume $k_{s}$ is at a maximum and $k_{d}$ at a minimum during this period. Hence, the approximate turnover rate $\left(\frac{d C}{d t} \sim\right)$ at eight particular ${ }^{5 \mathrm{Me} C}$ residues in the $p S 2$ promoter region may be estimated to be significantly less than $10 \mathrm{~min}$. In summary, the turnover of a subset of ${ }^{5 \mathrm{Me}} \mathrm{C}$ residues appears to be extremely rapid, particularly in some promoter regions (Figure 1D), validating Crick's concerns for one class of molecules that are involved in maintaining durable memories. The mechanisms that identify the DNA sequence context of the ${ }^{5 \mathrm{Me}} \mathrm{C}$ sites that turn over most rapidly remains an ongoing area of research.

The machinery responsible for the predominant DNA ${ }^{5 \mathrm{Me}} \mathrm{C}$ de-methylation activities contributing to turnover has been difficult to pin down in any tissue, let alone de-methylation in the brain, which might impact memory duration [21]. There are three phylogeneticallyrelated members in a family of non-enzymatic growth suppressors, the growth arrest and DNA-damage-inducible Gadd proteins (Gadd45a, $-45 \mathrm{~b}$ and $-45 \mathrm{~g}$ ). All three are associated with double stranded DNA repair machinery and are expressed in the brain [22]. Gadd45a was the first member to be linked to DNA demethylation, when it was isolated during a screen for embryonic cDNAs capable of activating co-transfected methylation-silenced gene encoding a SV40 early promoter-luciferase reporter [23]. Subsequent assays show that the transient overexpression of Gadd45a activity in HEK293T cells along with methylation-sensitive $S V 40, X b r a, B R E$, or TOP promoter driven reporters result in the ${ }^{5 \mathrm{Me}} \mathrm{CG}$ demethylation of the promoters and increased expression of all four reporters within the $24 \mathrm{~h}$ assay [23]. The results on reporter de-methylation parallel those using cotreatment with $\mathrm{AzaC}$ or expression of the same reporters 
in DNMT1-/- cells, except that Gadd45a expression further activates unmethylated as well as methylated reporters, while AzaC only activates methylated reporters. This suggests that Gadd45a activity not only contributes to the de-methylation of fully symmetrically methylated DNA (Figure $1 \mathrm{C}$ ), but may also overcome rapid endogenous re-methylation of $\mathrm{C}$ to ${ }^{5 \mathrm{Me}} \mathrm{C}$ in a fully unmethylated context that affects the dynamics of promoter activation and re-silencing.

The relative importance of the Gadds to the decay of DNA methylation was challenged by two studies, in particular. First, the transient expression of Gadd45a in cultured cells did not de-methylate or activate a methylated version of a methylation-sensitive Oct4/Pou $5 f 1$ promoter driven reporter transgene in HEK293T cells [21,24]. Second, mice lacking the Gadd45a variant show relatively normal development and normal methylation levels of the endogenous Oct4 promoter DNA and of global DNA [25]. However, a more recent study in embryonic stem (ES) cells suggests that Gadd45a acts in conjunction with other machinery to achieve demethylation on a subset of sequences, such as those in the Oct4 promoter. The demethylation and activation of methylation silenced $T K$ and Aprt promoter-reporter constructs and endogenous pluripotency genes (Oct4/Pou5f1, Nanog) require the co-expression of four genes involved in demethylation, Gadd45a, Tet1, Aid, and Mbd4 [26]. Silencing any one of these four genes abolished 50\% to $99 \%$ of the demethylating activity necessary to activate each of the four promoters. These data support the view that the Gadds are an essential part of complex multifaceted machinery involved in the sequence-specific control of DNA cytosine de-methylation and turnover. Yet, there are many unanswered questions and problems to be addressed concerning the role of Gadds in ${ }^{5 \mathrm{Me}} \mathrm{C}$ turnover. The three Gadd family variants are likely partially redundant or overlapping in function, but the phenotypes of double and triple Gadd mutants have not been reported. Turnover appears to be rapid, yet none of these studies examined Gadd45a expression constructs co-transfected with hemi-methylated reporters, in order to assay the contribution of endogenous remethylation and silencing to turnover rates after methylcytosine is removed from one strand of a ${ }^{5 \mathrm{Me}} \mathrm{CG} / \mathrm{G}^{5 \mathrm{Me}} \mathrm{C}$ sequence. Nor are their reports of the role of Gadds in the turnover of ${ }^{5 \mathrm{Me}} \mathrm{C}$ in the asymmetric $\mathrm{CH}$ dinucleotide context, where $\mathrm{H}$ is $\mathrm{T}$, C, or A (Figure 1B). Gene-region-specific ${ }^{5 \mathrm{Me}} \mathrm{CH}$ dinucleotide levels appear to be particularly well correlated with neuron-specific gene expression and the development of synaptic density in the human and mouse brain cortex [27].

There is initial evidence that three Gadds impact neural activity in the brain. Electroconvulsive treatment (ECT) induces proliferation of neural progenitors and dendritic development. ECT also induces the demethylation of specific ${ }^{5 \mathrm{Me}} \mathrm{CG}$ dinucleotides in the BDNF and FGF-B1 promoters in neural cells of the dentate gyrus of the hippocampus, but not measurable global DNA demethyation [28]. The approximate two-fold decrease in methylation of several CG dinucleotides in the BDNF and FGF-B1 promoters, which follows $4 \mathrm{~h}$ after ECT, was abolished in Gadd45b-/- mice. Transient 25- and eight-fold increases in expression of Gadd45b and $-45 g$ transcripts, respectively, peaked $1 \mathrm{~h}$ after ECT, but returned to base line levels $4 \mathrm{~h}$ post ECT. This suggests that Gadd $45 \mathrm{~b}$ and $-45 \mathrm{~g}$ may contribute to a dynamic demethylation response in the brain with the half-lives of some of the targeted ${ }^{5 \mathrm{Me}} \mathrm{C}$ residues measured in hours. The levels of Gadd45a transcripts did not change with ECT. In addition, further evidence for the dynamic role of Gadds in methylation turnover in neural cells comes from their co-expression with DNMTs. When Danio rerio retinal Müller glia transition from a quiescent supportive cells to multipotent neural progenitor cells (NPCs) following brain injury, homologs of Gadd45a and Gadd45g and four DNMTs (DNMT1, 4, 5, 7) are concomitantly induced [29]. Similarly, mouse brain NeuN-High neuronal cell nuclei with decondensed chromatin not only express elevated levels of transcripts involved in learning and memory and multipotency, but they also more highly express transcripts for Gadd45 $a$ and $-45 b$ and DNMT1 and $3 A$, relative to less epigenetically active normal-sized NeuN-Low neuronal cell nuclei [30]. In summary, the role of the Gadd family of repair proteins in the turnover of DNA methylation and memory duration remains an important problem worthy of further study, in spite of the apparent complexity of various published reports.

Recently the ten-eleven-translocation (TET) gene family (TET1, TET2, TET3) has emerged as central to removing ${ }^{5 \mathrm{Me}} \mathrm{C}$ residues [21]. TETs are DNA dioxygenases that catalyze the conversion of ${ }^{5 \mathrm{Me}} \mathrm{C}$ to another biologically active form 5 '-hydroxymethylcytosine $\left({ }^{5 \mathrm{hm}} \mathrm{C}\right)$ and require a double stranded $\beta$-helix for their activity. TETs have the potential go on to oxidize ${ }^{5 \mathrm{hm}} \mathrm{C}$ first to $5^{\prime}$-formylcytosine $\left({ }^{5 \mathrm{C}} \mathrm{C}\right)$ and then to $5^{\prime}$-carboxylcytosine $\left({ }^{5 \mathrm{ca}} \mathrm{C}\right)$. They perform all three reactions efficiently on ${ }^{5 \mathrm{Me}} \mathrm{C}$ modified DNA templates in vitro, but in vivo ${ }^{5 \mathrm{hm}} \mathrm{C}$ accumulates to much higher levels than the latter two products. DNA repair enzymes convert ${ }^{5 \mathrm{ca}} \mathrm{C}$ to $\mathrm{C}$ completing the turnover of ${ }^{5 \mathrm{Me}} \mathrm{C}$. TET generated ${ }^{5 \mathrm{hm}} \mathrm{Cs}$ in human ES cells and the mouse fetal and adult brain cortex are found almost exclusively in a CG context [27,31]. Thus, TETs have the potential to impact the turnover of a large subset of ${ }^{5 \mathrm{Me}} \mathrm{C}$ residues, but are unlikely to impact the large fraction of ${ }^{5 \mathrm{Me}} \mathrm{C}$ residues in the $\mathrm{CH}$ dinucleotide context. As an example of the potential of TETs to impact general methylation, cultured primary cells from benign smooth muscle leiomyoma tumors overexpress Tet1 and Tet3. 
They show increased global DNA ${ }^{5 \mathrm{hm}} \mathrm{C}$ relative to cultured primary myometrial cell controls. Partial RNAi silencing of Tet 1 or Tet3 expression for $24 \mathrm{~h}$ reduces global DNA ${ }^{5 \mathrm{hm}} \mathrm{C}$ by only $25 \%$, but greatly reduced the growth rate of leiomyoma cells [32]. As to the sequence specificity of TET activity, Tet1 binds in or proximal to the transcriptional start sites of 6,573 promoter sequences in ES cells, more than $85 \%$ of which were rich in CG dinucleotides and most of these were also enriched for ${ }^{5 \mathrm{Me}} \mathrm{C}$ and ${ }^{5 \mathrm{hm}} \mathrm{C}$ [33]. A more recent report shows that Tet1 activity results in the accumulation of ${ }^{5 \mathrm{hm}} \mathrm{C}$ at the edges of methylation rich CGIs, preventing the spread of methylation into normally unmethylated CG rich regions [34]. Taken together current evidence suggests that TETs act preferentially on a subset of ${ }^{5 \mathrm{Me}} \mathrm{C}$ residues concentrated in promoter regions. Tet1's demethylating activity appears to prevent aberrant methylation and silencing of many CG rich promoters to maintain appropriate levels of transcription.

All three TETs are well expressed in the brain and the importance of their synthesizing ${ }^{5 \mathrm{hm}} \mathrm{C}$ is only recently being understood. ${ }^{5 \mathrm{hm}} \mathrm{C}$ levels are three-fold to 50 -fold higher in some parts of the brain such as the cerebral cortex, than in most other organs [21,35]. The levels of ${ }^{5 \mathrm{hm}} \mathrm{C}$ are estimated at $40 \%$ of the ${ }^{5 \mathrm{Me}} \mathrm{C}$ levels in this region of the brain. In Purkinje and granule cell neurons in the brain ${ }^{5 \mathrm{hm}} \mathrm{C}$ is estimated to be $0.6 \%$ and $0.2 \%$ of total nucleotides, respectively [36]. Tet1 deficiency is associated with defects in neural development, altered expression of neuronal transcripts, and deficiencies in spatial learning and memory. For example, Tet1 knockout mice show a loss of memory extinction and reduced expression of critical neuronal regulated transcripts Arc, Fos, and Npas4 in the cortex and hippocampus [6]. CG dinucleotides in the Npas4 promoter, suspected to regulate its transcriptional activity, are hyper-methylated in Tet1 knockout mice. While ${ }^{5 \mathrm{hm}} \mathrm{C}$ levels are low in the cerebellum and hippocampus of 7-day-old mice, the levels of ${ }^{5 \mathrm{hm}} \mathrm{C}$ increase two- to five-fold, respectively, in the 6-week-old and adult mice [37]. In these later stages almost half of modified cytosines in CG context in these regions of brain are ${ }^{5 \mathrm{hm}} \mathrm{C}$. Other studies found that the levels of ${ }^{5 \mathrm{hm}} \mathrm{C}$ are low in the mouse brain cortex at conception, but increase rapidly to near adult levels 6 weeks later, increasing concordantly with increases in synaptogenesis [27,37]. Finally, in the fetal mouse brain Tet2 activity appears necessary to hydroxymethylate the few percent of ${ }^{5 \mathrm{Me}} \mathrm{C}$ residues destined to be demethylated at later states in development [27]. The tantalizing implication from these studies is that the TET-enzyme activity and ${ }^{5 \mathrm{hm}} \mathrm{C}$-dependent turnover rate of ${ }^{5 \mathrm{Me}} \mathrm{C}$ may be higher in the brain to assist with more rapid responses of the neuronal methylome to learning and memory. But these results only increase the concern for Crick's paradox, because more rapid TET-dependent turnover works against ${ }^{5 \mathrm{Me}} \mathrm{C}$-dependent memory duration.

\section{The turnover of nucleosomal histone side chain modifications}

Gene-specific nucleosomal histone PTMs are involved in memory formation, sometimes changing in a matter of minutes after a stimulus, and also contributing to durable memory formation $[3,4]$. There is only limited evidence that gene-specific histone PTMs are multi-generationally inherited and PTMs are rarely phylogenetically inherited among duplicated regions of DNA [11]. This suggests PTMs are more transient than DNA methylation and might turnover more rapidly. Turnover rates for nucleosomal histone variants and by default, histone PTMs, were approximated from experiments that examined changes in their levels over short time periods. A pioneering report in 1990 examined the incorporation of tritiated acetate into the major histone variants $(\mathrm{H} 2 \mathrm{~A}$, $\mathrm{H} 2 \mathrm{~B}, \mathrm{H} 3, \mathrm{H} 4$ ) in dividing cells without and with the addition of the HDAC inhibitor trichostatin A (TSA) [38]. This and subsequent related pulse-chase labeling experiments using HDAC inhibitors estimated the halflives $\left(t^{1 / 2}\right)$ of acetylated histone variants are in the range of 2 to $40 \mathrm{~min}\left(\frac{d C}{d t}=k_{s}\right)$ [39]. Another set of turnover rate measurements were made independent of the use of inhibitors or isotope incorporation in yeast with cells arrested in the G1 phase of growth. Turnover rate estimates may be made based on the approach-to-steadystate increases of histone incorporation into nucleosomes, after induction of transgenes expressing epitope tagged histone variants $\left(\frac{d C}{d t}=k_{s}\right)$. These studies are limited by the rate at which tagged variants are newly synthesized and reach a high enough steady state levels to compete maximally with endogenous histone variants. The rate of tagged histone $\mathrm{H} 2 \mathrm{~b}$ incorporation into nucleosomes suggests a turnover rate of less than $30 \mathrm{~min}$ for nucleosomes associated with both transcriptionally active and inactive genes [40]. Similarly, rate of incorporation of tagged histone $\mathrm{H} 3$ into nucleosomes, suggests half-life of the $\mathrm{H} 3$ variant may be less than $10 \mathrm{~min}$ for the 'hottest' most actively replaced nucleosomes relative to $\mathrm{H} 3$ incorporation into other nucleosomes, which turn over with half-lives estimated in hours or longer [41]. These studies also suggest that in yeast nucleosomal histone turnover rates were relatively low in actively transcribed gene regions, but high in the proximal regions of promoters.

A genome wide steady state measurement of histone variant turnover rates $\left(\frac{d C}{d t}=k_{s}\right)$ was made in cultured insect cells independent of transgene induction lag times using the methionine analog azidohomoalanine (Aha). Aha is rapidly incorporated into protein after its addition 
to cell culture media [42]. After non-dividing late log phase cells are given short pulses of Aha, nucleosomes are purified, and nucleosomal Aha is specifically chemically coupled to biotin. Newly made biotin-tagged nucleosomes are affinity purified and associated DNA quantified across the genome. Because the levels of nucleosomal Aha labeling of gene-region specific DNA sequences in active genes appears nearly complete after a 20 min pulse of Aha, the half-life $\left(t_{1 / 2}\right)$ for histone proteins within nucleosomes in these gene regions may estimated to be less than 10 to 20 min, but may occur more slowly in flanking promoter/ enhancer regions (Figure 1D). In summary, the discordance between the short half-lives of this major class of modified biomolecules implicated in memory formation and memory duration is extreme.

Following the symmetry argument in Crick's model for maintaining modifications, the symmetrical pairing of the four core histones (for example, two histone H4 subunits, two $\mathrm{H} 2 \mathrm{~b}$ subunits, and so on) in a nucleosome might direct the re-modification of hemi-modified histone pairs in nucleosomes. A model utilizing nucleosomal symmetry analogous to that for the activity of DNMT1 on hemimethylated DNA is imagined. However, one such study shows that the symmetrical pairing of differentially modified $\mathrm{H} 4$ subunits accounts for maintaining only a small fraction of the two histone H4 PTMs assayed, H4K20me2 and H4K20me3 [43]. Hence, nucleosomal symmetry may represent only a partial solution to the problem of histone PTM maintenance. Moreover, no such measurements taking into account the symmetry of PTMs have been reported for the brain.

Complex models for the deposition and turnover of nucleosomes with particular modified histone compositions have been proposed that preserve their position in chromatin, a process known as chromatin domain inheritance (CDI). CDI is of necessity linked to DNA replication, DNA repair, and transcription, but must be considered in any nucleosomal histone turnover model. Because it is hard to imagine a complete physical mechanism for the CDI of properly modified nucleosomes following replication or transcription, it is reassuring that numerous proteins and multiprotein complexes contributing to replicative CDI have been identified, including proliferating cell nuclear antigen, mini-chromosome maintenance complex, the histone chaperone anti-silencing factor 1 (ASF1), chromatin assembly factor 1 , and histone variant exchange complexes (for example, SWR1) [44-47]. As an example activity, histones $\mathrm{H} 3$ and $\mathrm{H} 4$ bound to ASF1 are deposited on both strands of the newly replicated DNA followed by H2A and H2B. Yet, in spite of progress understanding some of the mechanics of histone and nucleosome deposition and conservation beyond a DNA replication fork, the precise factors that determine $\mathrm{CDI}$ and how this entire process impacts durable memory-related gene expression remain illusive.

One major problem for understanding CDI has been that chromatin domains for nucleosomes were not previously thought of as DNA-sequence specific, and hence, the antiparallel symmetry of DNA did not seem relevant. However, a consensus rotational palindromic repeat of $10.5 \mathrm{bp}$ (R-YYYYYRRRRR-Y, $\mathrm{R}=$ purine, $\mathrm{Y}=$ pyrimidine) that bends correctly around and binds the eight core nucleosomal histones was revealed using advanced computational methods to examine tens of thousands of nucleosome-delimited 147 base pair (bp) DNA sequences from yeast, plants, and humans [48]. Typically on the order of several to 10 dinucleotides from among the 14 repeats of the DNA double helix have the correct sequence and orientation to bind and position the nucleosome (yellow dots, Figure 1C) [49]. Because DNA residues are contacting particular histone subunit amino acid residues, the exact histone variant composition and perhaps histone PTMs in the nucleosome appear to determine the sequence-specificity for nucleosome binding and positioning. For example, nucleosomes containing the histone variant $\mathrm{H} 2 \mathrm{AZ}$ that are enriched arround transcriptional start sites and nucleosomes containing the centromeric histone 3 (CENH3) that are highly enriched within centromeres each contact different dinucleotide consensus sequences [11,50,51]. In a recent study, Zovkic et al. [5] show that there is a rapid exchange of the two H2AZ variant nucleosomes immediately flanking the transcription start site of memory-related genes in the CA1 region of the hippocampus following fear conditioning (that is, remote memory and memory consolidation) [5]. In short, one key to the CDI of nucleosome specific histone PTMs associated with genes involved in memory maintenance may lie in the symmetrical doublestrand DNA sequence-specific code for nucleosome positioning.

\section{Current limitations and future studies on memory and molecular turnover}

It is worth noting that most of the literature on the turnover of chromatin structures does not come from the CNS. With few exceptions, the examples measuring molecular turnover associated with direct measurements of memory acquisition, consolidation, remote (long-term) memory, and extinction come from the best-studied model system for learning-related plasticity, the hippocampus. Yet, the latter of these memory processes involve a dialog with neurons in other regions of the brain such as the neocortex [52,53]. Linked cortical neurons are undoubtedly being reprogrammed through dynamic changes in epitype that are not being measured. Perhaps the extension of new technologies, 
such as the fluorescence activated nuclear sorting or isolation of nuclei tagged in specific cell types (INTACT) in the brain will enable the analysis of turnover in different classes of neurons from multiple regions of the brain $[27,30,54]$.

Also beyond the scope of current research is the dissecting possibility that the thousands of synaptic connections formed by one neuron are recorded or programmed as combinatorial genome-wide changes to numerous different chromatin structures that must be maintained or strengthened for remote memories [55]. A cubic millimeter of the mammalian neocortex contains nearly a hundred thousand neurons with as many as an hundred million synapses [56], whose synaptic strength must be rapidly regulated. It is hard to conceive that changes in epitype in the nucleus of each neuron direct such complexity, even if the combinatorial capacity exists in the epigenome. Non-chromatin associated decentralized epigenetic phenomena such as the localization of mRNAs (for example, MKK7, PKM $)$ and non-coding RNAs (for example, miR-124) contribute to neurite- and synapse-specific gene expression [57-59]. Further, memory-related transcriptional regulatory proteins (for example, CRTC1) may be localized near synapses and subsequently transported to the nucleus to couple synaptic transmission with transcription [60,61]. Yet, RNA and protein transport and their cytoplasmic positioning for remote memory may be programmed by chromatin-modifications, modifications that must be maintained for some period and are subject to molecular turnover. Such unresolved issues highlight the early pioneering stage of research on the epigenetics of long-term memory.

\section{Conclusions}

Crick's model highlighting the importance of molecular turnover and the role of molecular symmetry to memory duration appears to have been way ahead of its time and is worthy of serious consideration as we explore the molecular bases of memory. Loss of normal epigenetic control and defects in remote memory are part of most cognitive disorders, including Alzheimer's disease, Rett syndrome, Rubinstein-Taybi syndrome, Prader-Willi syndrome, Schizophrenia, Fragile X mental retardation, and major depression $[6,7,62]$. Defects in histone PTMs and DNA methylation have been strongly implicated in the loss of cognitive function and memory and most of these disorders. Beyond the role of symmetry in CG methylation, little is known about the contribution of molecular symmetry to maintaining modifications in relevant protein complexes such as the nucleosome. Closing the gap between understanding memory duration and the maintenance of chromatin modifications in the face of rapid molecular turnover appears paramount to the study of neurobiology and neurodegenerative disease.

\section{General abbreviations}

AzaC (5-aza-2'-deoxycytidine), Aha (azidohomoalanine), bp (base pair), BER (base excision repair), CDI (chromatin domain inheritance), CGI (CG rich Islands), CNS (central nervous system), ECT (Electroconvulsive treatment), ES cells (embryonic stem cells), HEK293T cells (human embryonic kidney 293 cells), histone PTM (histone post-translational modification), INTACT (isolation of nuclei tagged in specific cell types) [63,64], NPC (neural progenitor cell), ${ }^{5 \mathrm{Me}} \mathrm{C}$ (5'-methylcytosine), ${ }^{5 \mathrm{hm}} \mathrm{C}\left(5^{\prime}\right.$ hydroxymethylcytosine), ${ }^{5 \mathrm{f}} \mathrm{C}$ ( $5^{\prime}$-formylcytosine), ${ }^{5 \mathrm{ca}} \mathrm{C}$ (5'-carboxylcytosine), RNAi (RNA interference), TDG (thymine-DNA glycosylase).

\section{Protein/gene abbreviations}

Aid/AICDA (Activation-Induced Cytidine Deaminase), Aprt (adenine phosphoribosyltransferase), APC/PPP1R46 (Adenomatous Polyposis Coli), ARC (Activity-regulated cytoskeleton-associated protein), ASF1 (histone chaperone anti-silencing factor 1), BDNF (Brain-derived neurotrophic factor), BRE/BRACC45 (Brain And Reproductive Organ-Expressed), BRN2/ POU3F2 (Brain-specific $2 / \mathrm{N}$ gene, POU domain class 3 homeobox 2), CENH3 (centromeric histone 3), CRTC1 (CREB-regulated transcriptional coactivator), CRYAA/ CRYA1 (Crystallin, Alpha A), DAZ1/SPGY (Deleted In Azoospermia 1), DNMTs (DNA methyltransferases 1, 3A, 3B from mammals and 1 4, 5, 7 from fish), DRM1, DRM2, CMT3 (RNA directed de novo DNA methyltransferases), FGF-B1/FGF2 (Fibroblast growth factor 1 basic), Fos (FBJ Murine Osteosarcoma Viral Oncogene Homolog), GADD45a, GADD $45 \beta$ and GADD45g (DNA cytosine demethylases, Growth arrest DNA damage inducible protein isoforms), HDAC (histone deacetylase), H2AZ (histone 2a, isoform Z), Mbd4/MED1 (Methyl-CpG Binding Domain Protein 4), MeCP2 (methyl-CpG binding protein 2), MKK7 (mitogen-activated protein kinase kinase 7), MYD118 (myeloid differentiation primary response factor), microRNA 124 (miR124), Npas4 (Neuronal PAS Domain Protein 4), NeuN/ RBFOX3 (Neuronal nuclei, Hexaribonucleotide Binding Protein 3), OCT4/POU5F1 (Octamer-binding transcription factor 4, $\mathrm{PKM} \zeta$ (protein kinase $\mathrm{M}$ zeta), POU domain, class 5 , transcription factor 1 ), $\mathrm{PP} 1 \mathrm{C} / \mathrm{PP} 1 \mathrm{C} \gamma / \mathrm{PPP} 1 \mathrm{G}$ (serine threonine protein phosphatase 1, gamma subunit), pS2/BEC1 (Breast Cancer Estrogen-Inducible Protein, Trefoil Factor 1), RELN (Reelin), SV40 (simian vacuolating virus 40), TET1, 2, 3 (ten-eleven-translocation DNA dioxygenases), TK1 (Thymidine kinase 1), TOP1 (Topoisomerase DNA 1), Xbra (Xenopus brachyury). 


\section{Competing interests}

The author declares that he has no competing interests.

\section{Acknowledgements}

Several colleagues at the University of Georgia and Emory University, Alicia Smith, Robert Schmitz, Roger Deal, Mary Anne Della-Fera, Dave Hall, Emily Rose England, Natalie Hohos, and Ping Yu, made helpful comments on the manuscript. National Institutes of Health NIDDK Grants DK096300 and DK100392 support related research.

Received: 29 October 2014 Accepted: 28 November 2014 Published: 9 December 2014

\section{References}

1. Crick F: Memory and molecular turnover. Nature 1984, 312:101

2. Sweatt JD: The emerging field of neuroepigenetics. Neuron 2013, 80:624-632.

3. Zovkic IB, Guzman-Karlsson MC, Sweatt JD: Epigenetic regulation of memory formation and maintenance. Learn Mem 2013, 20:61-74.

4. Rudenko A, Tsai LH: Epigenetic regulation in memory and cognitive disorders. Neuroscience 2014, 264:51-63.

5. Zovkic IB, Paulukaitis BS, Day JJ, Etikala DM, Sweatt JD: Histone H2A.Z subunit exchange controls consolidation of recent and remote memory. Nature 2014, 515:582-586.

6. Rudenko A, Dawlaty MM, Seo J, Cheng AW, Meng J, Le T, Faull KF, Jaenisch R, Tsai LH: Tet1 is critical for neuronal activity-regulated gene expression and memory extinction. Neuron 2013, 79:1109-1122.

7. Levenson JM, Sweatt JD: Epigenetic mechanisms in memory formation. Nat Rev Neurosci 2005, 6:108-118.

8. Bostick M, Kim JK, Esteve PO, Clark A, Pradhan S, Jacobsen SE: UHRF1 plays a role in maintaining DNA methylation in mammalian cells. Science 2007, 317:1760-1764.

9. Yu N-K, Baek SH, Kaang B-K: DNA methylation-mediated control of learning and memory. Mol Brain 2011, 4:5.

10. Day JJ, Sweatt JD: DNA methylation and memory formation. Nat Neurosci 2010, 13:1319-1323.

11. Meagher RB, Mussar KJ: The influence of DNA sequence on epigenomeinduced pathologies. Epigenetics Chromatin 2012, 5:11-35.

12. Morris MJ, Adachi M, Na ES, Monteggia LM: Selective role for DNMT3a in learning and memory. Neurobiol Learn Mem 2014, 115:30-37.

13. Miller CA, Sweatt JD: Covalent modification of DNA regulates memory formation. Neuron 2007, 53:857-869.

14. Lai F, Shiekhattar R: Where long noncoding RNAs meet DNA methylation. Cell Res 2014, 24:263-264.

15. Matzke MA, Mosher RA: RNA-directed DNA methylation: an epigenetic pathway of increasing complexity. Nat Rev Genet 2014, 15:394-408.

16. Rajasethupathy P, Antonov I, Sheridan R, Frey S, Sander C, Tuschl T, Kandel ER: A role for neuronal piRNAs in the epigenetic control of memory-related synaptic plasticity. Cell 2012, 149:693-707.

17. Schimke RT: Methods for analysis of enzyme synthesis and degradation in animal tissues. Methods Enzymol 1975, 40:241-266.

18. Yamagata Y, Szabo P, Szuts D, Bacquet C, Aranyi T, Paldi A: Rapid turnover of DNA methylation in human cells. Epigenetics 2012, 7:141-145.

19. Ueno M, Katayama K, Yamauchi H, Yasoshima A, Nakayama H, Doi K: Repair process of fetal brain after 5-azacytidine-induced damage. Eur J Neurosci 2006, 24:2758-2768.

20. Metivier R, Gallais R, Tiffoche C, Le Peron C, Jurkowska RZ, Carmouche RP, Ibberson D, Barath P, Demay F, Reid G, Benes V, Jeltsch A, Gannon F, Salbert G: Cyclical DNA methylation of a transcriptionally active promoter. Nature 2008, 452:45-50.

21. Wu H, Zhang Y: Reversing DNA methylation: mechanisms, genomics, and biological functions. Cell 2014, 156:45-68.

22. Niehrs C, Schafer A: Active DNA demethylation by Gadd45 and DNA repair. Trends Cell Biol 2012, 22:220-227.

23. Barreto G, Schafer A, Marhold J, Stach D, Swaminathan SK, Handa V, Doderlein G, Maltry N, Wu W, Lyko F, Niehrs C: Gadd45a promotes epigenetic gene activation by repair-mediated DNA demethylation. Nature 2007, 445:671-675.

24. Jin SG, Guo C, Pfeifer GP: GADD45A does not promote DNA demethylation. PLoS Genet 2008, 4:e1000013.
25. Engel N, Tront JS, Erinle T, Nguyen N, Latham KE, Sapienza C, Hoffman B, Liebermann DA: Conserved DNA methylation in Gadd45a(-/-) mice. Epigenetics 2009, 4:98-99.

26. Sabag O, Zamir A, Keshet I, Hecht M, Ludwig G, Tabib A, Moss J, Cedar H: Establishment of methylation patterns in ES cells. Nat Struct Mol Biol 2014, 21:110-112.

27. Lister R, Mukamel EA, Nery JR, Urich M, Puddifoot CA, Johnson ND, Lucero J, Huang Y, Dwork AJ, Schultz MD, Yu M, Tonti-Filippini J, Heyn H, Hu S, Wu JC, Rao A, Esteller M, He C, Haghighi FG, Sejnowski TJ, Behrens MM, Ecker JR: Global epigenomic reconfiguration during mammalian brain development. Science 2013, 341:1237905.

28. Ma DK, Jang MH, Guo JU, Kitabatake Y, Chang ML, Pow-Anpongkul N, Flavell RA, Lu B, Ming GL, Song H: Neuronal activity-induced Gadd45b promotes epigenetic DNA demethylation and adult neurogenesis. Science 2009, 323:1074-1077.

29. Powell C, Grant AR, Cornblath E, Goldman D: Analysis of DNA methylation reveals a partial reprogramming of the Muller glia genome during retina regeneration. Proc Natl Acad Sci U S A 2013, 110:19814-19819.

30. Yu P, McKinney EC, Kandasamy MM, Albert AL, Meagher RB: Characterization of brain cell nuclei with decondensed chromatin. Dev Neurobio/ 2014. doi:10.1002/dneu.22245.

31. Yu M, Hon GC, Szulwach KE, Song CX, Zhang L, Kim A, Li X, Dai Q, Shen Y, Park B, Min JH, Jin P, Ren B, He C: Base-resolution analysis of 5hydroxymethylcytosine in the mammalian genome. Cell 2012, 149:1368-1380.

32. Navarro A, Yin P, Ono M, Monsivais D, Moravek MB, Coon JS 5th, Dyson MT, Wei JJ, Bulun SE: 5-hydroxymethylcytosine promotes proliferation of human uterine leiomyoma: a biological link to a new epigenetic modification in benign tumors. J Clin Endocrinol Metab 2014, 99:E2437-E2445.

33. Williams K, Christensen J, Pedersen MT, Johansen JV, Cloos PA, Rappsilber J, Helin K: TET1 and hydroxymethylcytosine in transcription and DNA methylation fidelity. Nature 2011, 473:343-348.

34. Jin C, Lu Y, Jelinek J, Liang S, Estecio MR, Barton MC, Issa JP: TET1 is a maintenance DNA demethylase that prevents methylation spreading in differentiated cells. Nucleic Acids Res 2014, 42:6956-6971.

35. Globisch D, Munzel M, Muller M, Michalakis S, Wagner M, Koch S, Bruckl T, Biel M, Carell T: Tissue distribution of 5-hydroxymethylcytosine and search for active demethylation intermediates. PLOS One 2010, 5:e15367.

36. Kriaucionis S, Heintz N: The nuclear DNA base 5-hydroxymethylcytosine is present in Purkinje neurons and the brain. Science 2009, 324:929-930.

37. Szulwach KE, Li X, Li Y, Song CX, Wu H, Dai Q, Irier H, Upadhyay AK, Gearing M, Levey Al, Vasanthakumar A, Godley LA, Chang Q, Cheng X, He C, Jin P: 5-hmC-mediated epigenetic dynamics during postnatal neurodevelopment and aging. Nat Neurosci 2011, 14:1607-1616.

38. Yoshida M, Kijima M, Akita M, Beppu T: Potent and specific inhibition of mammalian histone deacetylase both in vivo and in vitro by trichostatin A. J Biol Chem 1990, 265:17174-17179.

39. Waterborg $\mathrm{JH}$ : Dynamics of histone acetylation in vivo. A function for acetylation turnover? Biochem Cell Biol 2002, 80:363-378.

40. Jamai A, Imoberdorf RM, Strubin M: Continuous histone H2B and transcription-dependent histone $\mathrm{H} 3$ exchange in yeast cells outside of replication. Mol Cell 2007, 25:345-355.

41. Dion MF, Kaplan T, Kim M, Buratowski S, Friedman N, Rando OJ: Dynamics of replication-independent histone turnover in budding yeast. Science 2007, 315:1405-1408.

42. Deal RB, Henikoff JG, Henikoff S: Genome-wide kinetics of nucleosome turnover determined by metabolic labeling of histones. Science 2010, 328:1161-1164.

43. Chen X, Xiong J, Xu M, Chen S, Zhu B: Symmetrical modification within a nucleosome is not required globally for histone lysine methylation. EMBO Rep 2011, 12:244-251.

44. Margueron R, Reinberg D: Chromatin structure and the inheritance of epigenetic information. Nat Rev Genet 2010, 11:285-296.

45. Jones PA, Liang G: Rethinking how DNA methylation patterns are maintained. Nat Rev Genet 2009, 10:805-811.

46. Day JJ, Sweatt JD: Cognitive neuroepigenetics: a role for epigenetic mechanisms in learning and memory. Neurobiol Learn Mem 2011, 96:2-12.

47. Buchanan L, Durand-Dubief M, Roguev A, Sakalar C, Wilhelm B, Stralfors A, Shevchenko A, Aasland R, Shevchenko A, Ekwall K, Francis Stewart A: The Schizosaccharomyces pombe JmjC-protein, Msc1, prevents $\mathrm{H} 2 \mathrm{~A} . \mathrm{Z}$ 
localization in centromeric and subtelomeric chromatin domains. PLoS Genet 2009, 5:e1000726.

48. Flores O, Deniz O, Soler-Lopez M, Orozco M: Fuzziness and noise in nucleosomal architecture. Nucleic Acids Res 2014, 42:4934-4946.

49. Trifonov EN: Cracking the chromatin code: precise rule of nucleosome positioning. Phys Life Rev 2011, 8:39-50.

50. Albert I, Mavrich TN, Tomsho LP, Qi J, Zanton SJ, Schuster SC, Pugh BF: Translational and rotational settings of H2A.Z nucleosomes across the Saccharomyces cerevisiae genome. Nature 2007, 446:572-576.

51. Gent Jl, Schneider KL, Topp CN, Rodriguez C, Presting GG, Dawe RK: Distinct influences of tandem repeats and retrotransposons on $\mathrm{CENH} 3$ nucleosome positioning. Epigenetics Chromatin 2011, 4:3.

52. Wierzynski CM, Lubenov EV, Gu M, Siapas AG: State-dependent spike-timing relationships between hippocampal and prefrontal circuits during sleep. Neuron 2009, 61:587-596.

53. Sweegers CC, Takashima A, Fernandez G, Talamini LM: Neural mechanisms supporting the extraction of general knowledge across episodic memories. Neuroimage 2014, 87:138-146.

54. Dammer EB, Duong DM, Diner I, Gearing M, Feng Y, Lah JJ, Levey Al, Seyfried NT: Neuron enriched nuclear proteome isolated from human brain. J Proteome Res 2013, 12:3193-3206.

55. Lu Y, Qu W, Min B, Liu Z, Chen C, Zhang C: Modelling epigenetic regulation of gene expression in 12 human cell types reveals combinatorial patterns of cell-type-specific genes. IET Syst Biol 2014, 8:104-115.

56. da Costa NM, Martin KA: Sparse reconstruction of brain circuits: or, how to survive without a microscopic connectome. Neuroimage 2013, 80:27-36.

57. Ho VM, Dallalzadeh LO, Karathanasis N, Keles MF, Vangala S, Grogan T, Poirazi P, Martin KC: GluA2 mRNA distribution and regulation by miR-124 in hippocampal neurons. Mol Cell Neurosci 2014, 61:1-12.

58. Feltrin D, Fusco L, Witte H, Moretti F, Martin K, Letzelter M, Fluri E, Scheiffele P, Pertz O: Growth cone MKK7 mRNA targeting regulates MAP1b-dependent microtubule bundling to control neurite elongation. PLOS Biol 2012, 10:e1001439.

59. Ho VM, Lee JA, Martin KC: The cell biology of synaptic plasticity. Science 2011, 334:623-628.

60. Ch'ng TH, Uzgil B, Lin P, Avliyakulov NK, O'Dell TJ, Martin KC: Activity-dependent transport of the transcriptional coactivator CRTC1 from synapse to nucleus. Cell 2012, 150:207-221.

61. Ch'ng TH, Martin KC: Synapse-to-nucleus signaling. Curr Opin Neurobiol 2011, 21:345-352.

62. Rudenko A, Tsai LH: Epigenetic modifications in the nervous system and their impact upon cognitive impairments. Neuropharmacology 2014 80:70-82.

63. Deal RB, Henikoff S: The INTACT method for cell type-specific gene expression and chromatin profiling in Arabidopsis thaliana. Nat Protoc 2011, 6:56-68.

64. Deal RB, Henikoff S: A simple method for gene expression and chromatin profiling of individual cell types within a tissue. Dev Cell 2010, 18:1030-1040

doi:10.1186/1756-8935-7-37

Cite this article as: Meagher: 'Memory and molecular turnover,' 30 years after inception. Epigenetics \& Chromatin 2014 7:37.

\section{Submit your next manuscript to BioMed Central and take full advantage of:}

- Convenient online submission

- Thorough peer review

- No space constraints or color figure charges

- Immediate publication on acceptance

- Inclusion in PubMed, CAS, Scopus and Google Scholar

- Research which is freely available for redistribution 